\title{
A Review of Computational Fluid Dynamics Simulations on PEFC Performance
}

\section{Chen $\mathrm{Y}^{1 *}$, Enearu OL ${ }^{1}$, Montalvao $\mathrm{D}^{2}$ and Sutharssan $\mathrm{T}^{1}$}

${ }^{1}$ School of Engineering and Technology, University of Hertfordshire, College Lane, Hatfield, Hertfordshire, AL10 9AB, UK ${ }^{2}$ Bournemouth University, Department of Design and Engineering, Faculty of Science and Technology, Poole BH12 5BB, UK.

\begin{abstract}
Among the number of fuel cells in existence, the proton exchange fuel cell (PEFC) has been favoured because of its numerous applications. These applications range from small power generation in cell phones, to stationary power plants or vehicular applications. However, the principle of operation on PEFCs naturally leads to the development of water from the reaction between hydrogen and oxygen. Computational fluid dynamics (CFD) has played an important role in many research and development projects. From automotive to aerospace and even medicine, to the development of fuel cells, by making it possible to investigate different scenarios and fluid flow patterns for optimal performance. CFD allows for in-situ analysis of PEFCs, by studying fluid flow and heat and mass transfer phenomena, thus reducing the need for expensive prototypes and cutting down test-time by a substantial amount. This paper aims at investigating the advances made in the use of CFD as a technique for the performance and optimisation of PEFCs to identify the research and development opportunities in the field, such as the performance of a novel PEFC, with focus on the underlying physics and in-situ analysis of the operations.
\end{abstract}

Keywords: Proton exchange fuel cell (PEFC); Fuel cell (FC); Computational fluid dynamics (CFD); Validation

\section{Introduction}

The world is quickly becoming aware of the need to resolve issues associated with energy and climate changes. Sustainable energy is being developed and is aimed at handling greenhouse effects due to gas emissions and limited availability of fossil fuels by combining social awareness with technologies [1]. PEFCs have been referred to as an effective source of power production with very attractive energy transformation technologies, low operating temperature, high efficiency, zero emissions, quick start-up time and silence during operations [2-5]. Fuel cells have also been identified as a proposed solution to greenhouse emission problems due to operations [6]. Fuel cells come in various forms and are suitable for automotive, stationary, and portable system applications [7].

The versatility of FC applications ranges from small devices capable of supplying just a few watts of electricity to power plants generating power in the megawatts range. However, an individual fuel cell usually delivers low voltages and high currents. Typical voltage and current values range from 0.4 to $0.9 \mathrm{~V}$ and from 0.5 to $1.0 \mathrm{~A} / \mathrm{cm}^{2}$ respectively after losses [8]. As shown in Figure 1, in order for fuel cells to produce high voltages, a stack is made up by connecting a number of fuel cells in series, separated by bipolar plates [9]. The different fuel cells are categorised according to the type of electrolyte they use. Both advantages and disadvantages can be found with respect to temperature, size, fuel, purity, lifetime and cost. This is because each type of fuel cell requires particular materials and fuels that may be restricted to certain applications [10]. The various categories of fuel cells include:

1. PEMFC or PEFC - Proton Exchange (Membrane) Fuel Cells (also referred to in the literature as Polymer Electrolyte Membrane Fuel Cell).

2. DMFC - Direct Methanol Fuel Cell.

3. PAFC - Phosphoric Acid Fuel Cell.

4. AFC - Alkaline Fuel Cell.

\section{SOFC - Solid Oxide Fuel Cell.}

6. MCFC - Molten Carbonate Fuel Cell.

The PEFCs are usually made up of polymer electrolyte membranes (commonly Nafion ${ }^{\circledR}$ ) as a proton conductor and Platinum as a catalyst [11]. PEFCs have the ability to satisfy vehicular, domestic and larger stationary energy requirements. In the upcoming years, it is envisaged that the fuel cell applications will include automotive powertrains, distributed power generation and portable devices such as batteries [1,12]. Significant research and development efforts have gone into PEFC technologies over the past few years, thus leading to an increase in power density, efficiency and reliability of the existing PEFCs $[11,13]$. Nevertheless, the increased level of research has given little attention to the underlying physics of the transport phenomena of fluid and gases within the fuel cells. As a result of the highly reactive and compact nature of the fuel cell, in-situ measurements cannot be easily carried out during an operation [14]. Hence, computational fluid dynamics (CFD) modelling and simulations have been preferred to help in providing a better understanding of transportation of fluids and gases within the fuel cell [15].

\section{Fundamentals of the PEFC}

The operating principle of a PEFC is relatively simple: it involves the feeding of hydrogen into the cell to be oxidised at the anode, while the oxygen is reduced at the cathode after being carried in by an air feed stream [16]. As shown in Figure 1, a common fuel cell structure

*Corresponding author: Chen $\mathrm{Y}$, School of Engineering and Technology University of Hertfordshire, College Lane, Hatfield, Hertfordshire, AL10 9AB, UK, Tel: +44 1707 28400; E-mail: y.k.chen@herts.ac.uk

Received October 15, 2016; Accepted December 05, 2016; Published December 10, 2016

Citation: Chen Y, Enearu OL, Montalvao D, Sutharssan T (2016) A Review of Computational Fluid Dynamics Simulations on PEFC Performance. J Appl Mech Eng 5: 241. doi: 10.4172/2168-9873.1000241

Copyright: @ 2016 Chen Y, et al. This is an open-access article distributed under the terms of the Creative Commons Attribution License, which permits unrestricted use, distribution, and reproduction in any medium, provided the original author and source are credited. 


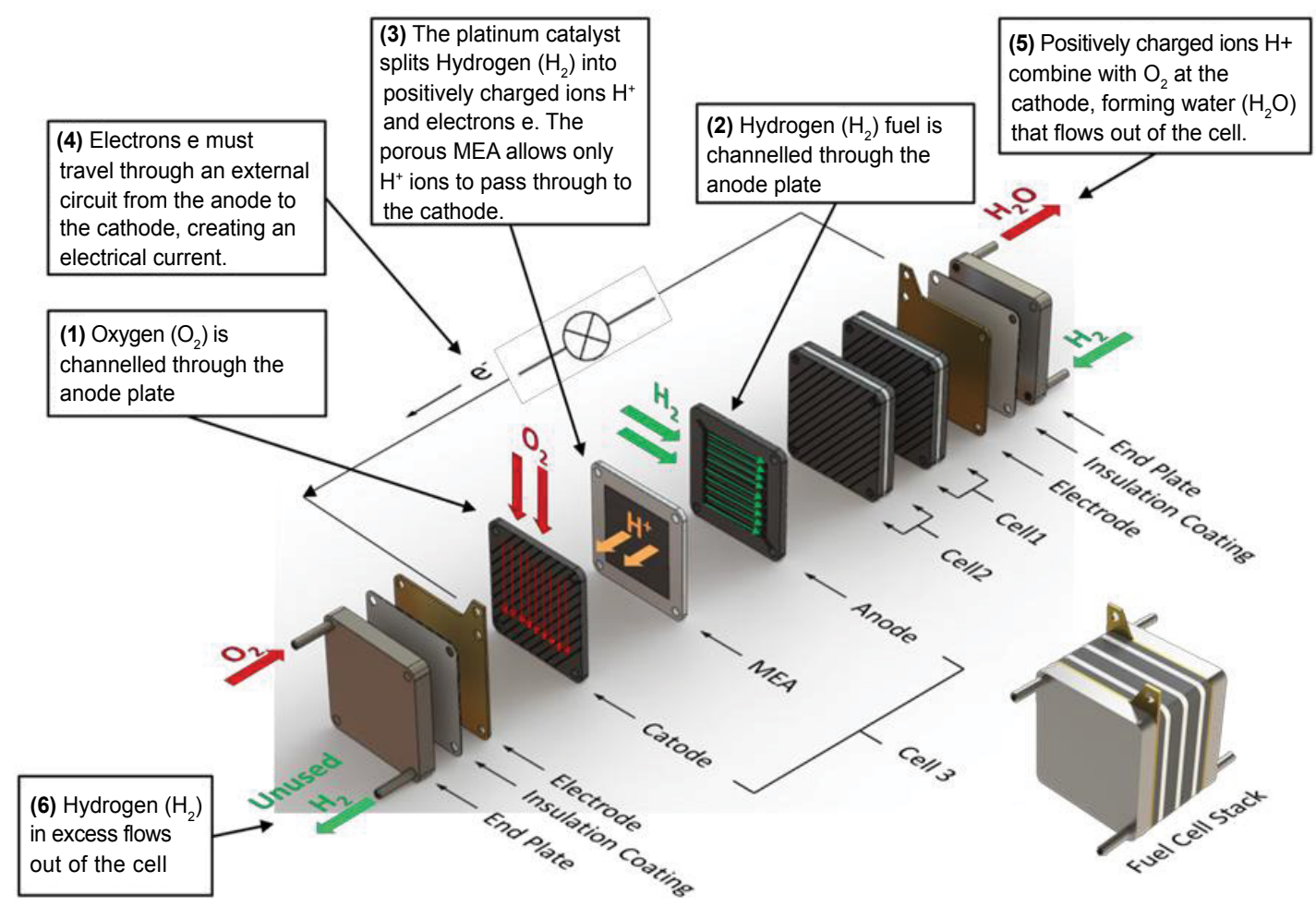

Figure 1: Layout and operation of a typical PEM fuel cell stack.

also known as membrane electrode assembly (MEA) is made up of an ion-conducting electrolyte material layered in between a porous anode and cathode electrodes. The hydrogen is supplied to this porous anode, while the oxygen is supplied to the cathode, commonly by feeding air into the cathode [17]. The input fuel of hydrogen passes over a negatively charged anode electrode, where it is split into $\mathrm{H}^{+}$ions and e-electrons. The electrons are then transported through an external circuit to produce electric current, while oxygen passes over a positively charged cathode electrode. The ions go through the electrolyte to the positively charged electrode and react with one another to produce $\mathrm{H}_{2} \mathrm{O}$ (water) and heat as by-products.

Furthermore, the straight transformation of the chemical energy of covalent bonds into electrical energy occurs as a result of the split of the hydrogen and oxygen by the electrolyte also referred to as a separator. The electron transfer in this process takes a long period of time, which allows direct gathering of electrons, thus leading to fuel efficiency more than two times higher than that in ICEs (Internal Combustion Engines) [18]. The direct current electricity that is produced as a result of the flow of electrons from the anode to the cathode within the fuel cell is the main product. It is also worthy to note that the amount of current produced depends on the amount of reactant fuels or gases supplied, chemical activity and power loss within the fuel stack. However, the production of current is constant over time, unlike in batteries where it decreases, because there is no chemical transformation of the fuel cell components involved. Hence, the fuel cell can continue generating power, provided that the supply of reactant gases remains constant for the required period [17]. The ability to continue producing power is one of the many benefits of PEFCs.

\section{Effects of parameters on performance of the PEFC}

For the PEFC to perform as intended, it is important that appropriate operating parameters are observed at all times [5]. These operating parameters can include temperature of the Fuel Cell (FC), operating pressure, heat loss, flow distribution, steam reforming, relative humidity of reactant gases, stoichiometric ratio, water distribution, current density and performance (polarisation) curve $[19,20]$. Observation of these parameters can be done with the aid of a built-in monitoring system that shows these parameters on a screen and can also shut down the fuel cell in emergency situations. Santarelli and Torchio [21] pointed out the importance of understanding what effects these parameters have on the PEFC so that supplementary costs associated with external systems that are employed to control these variables can be reduced. This is a result of the fuel cell being a complex system, consisting of interconnected parts that depend on each other in order to achieve the aim of energy production. This implies that degradation mechanisms are interconnected and can result from the individual degradation of one part leading to the deterioration of other parts and components of the FC [22].

\section{Water management}

The performance of the PEFCs can be influenced by a number of factors and operating conditions such as temperature, pressure and humidification of the reactant gases [23]. However, to a large extent, the performance is dependent on the hydration of the polymer membrane, where the water balance is dependent on the fuel cell current and water content of fuel and oxidant gas stream [24]. When the current density goes beyond a certain threshold, the delivery of water by electro-osmotic drag and oxygen-reduction reaction (ORR) overtakes the water removal from the cathode catalyst [25] hence, the excess water accumulates, flooding the electrode and reducing the rate of oxygen being transported to the catalyst. It is this flooding that limits the mass-transport ability of the electrode which then leads to a quick 
rise in the cathode overvoltage. A decrease in the FC power output is the end result $[26,27]$.

Without proper water management to keep up the constant energy production rate, especially at the cathode, flooding of the pores in the catalyst and gas diffusion layers is likely to occur. This can lead to a reduction in cell performance as a result of the inability of reactants to reach active catalyst sites. However, a certain quantity of water is required to ensure the optimum operation of the fuel cell because the proton conductivity of the membrane depends on humidification. This level of humidification is required to avoid membrane dehydration and water vapour condensation that could lead to a reduction in proton conductivity and an increase in ohmic losses and overheating of the stack $[25,28]$. Table 1 illustrates the effects of water content on the parts and operations of a PEFC. It is worthy to note that corrosion can occur as a result of the electrochemical nature of the reactions within the PEFC during operations [29-34].

A number of interacting factors and mechanisms such as flooding, dehydration and corrosion contribute to the degradation and performance of a FC. Therefore, better understanding of the transportation phenomena of liquid water in the fuel cell may lead to substantial performance gains and an enhancement in the lifetime of the fuel cell [35]. Li et al. [36] have reported the following contributing issues that hinder the performance of the cathode; 1) Slow kinetics of the oxygen reduction reaction at the cathode unlike the hydrogen oxidation reaction at the anode, 2) Difficulty in removing water at the cathode leading to a limitation of the mass transport.

The liquid water produced due to the electrochemical reactions in the fuel cell in addition to water from humidified inlet gas, makes it possible to keep the required level of hydration in the membrane
[37] The water generated as a by-product during power-generating operations of the fuel cell is unwelcome. Recent development efforts have led to the production of PEFC models with built-in water management systems to manage water and humidity in the fuel cell. However, the issue with water generated during operation of the fuel cell prevails, eventually leading to unwanted flooding [38] Although the water production within the fuel cell during operation is unavoidable because it is a by-product of the hydrogen fuel reaction during the conversion to electrical energy, it exists and remains in the liquid state as a result of the low operating temperature of the PEFC [39]. Figure 2 shows a schematic illustration of the process of water production within the PEFC.

Liquid water is generated in the cathode and is transported across the electrolyte by the electro-osmotic drag from the anode to the cathode. The oxygen reduction reaction (ORR) is a very important process in fuel cell modelling that occurs at the cathode and the hydrogen oxidation reaction $(\mathrm{HOR})$ at the anode $[15,40,41]$ can be expressed as flows:

$$
\begin{aligned}
& 1 / 2 \mathrm{O}_{2}+2 \mathrm{H}^{+}+2 \mathrm{e}^{-} \rightarrow \mathrm{H}_{2} \mathrm{O} \\
& \mathrm{H}_{2} \rightarrow 2 \mathrm{H}^{+}+2 \mathrm{e}^{-}
\end{aligned}
$$

The addition of the two half-cell reactions (1) and (2), which is exothermic, gives the combustion reaction (3) of the fuel cell in:

$$
\mathrm{H}_{2}+1 / 2 \mathrm{O}_{2} \rightarrow \mathrm{H}_{2} \mathrm{O}+\text { Electricity }+ \text { Heat }
$$

The formation of water in the PEFC actually leads to a 2-phase flow in the channels which consists of liquid water and gas/vapour, thus increasing the complexity of the problem of water management

\begin{tabular}{|c|c|c|c|}
\hline & Dehydration & Humidified & Flooding \\
\hline \multirow{4}{*}{$\begin{array}{c}\text { Overall } \\
\text { performance }\end{array}$} & Significant drop in cell potential, & \multirow{4}{*}{$\begin{array}{l}\text { Normal power output based on set } \\
\text { operating conditions. }\end{array}$} & Drop in cell voltage. \\
\hline & leading to power loss. & & Significant reduction in performance and lifetime. \\
\hline & $\begin{array}{l}\text { Instant and long-term degradation in } \\
\text { cell operations. }\end{array}$ & & Reduction in the \\
\hline & Reduction in cell performance & & \\
\hline \multirow{2}{*}{ Catalyst layer } & \multirow{2}{*}{--} & \multirow{2}{*}{---} & Reduction in the transport rate of reactants. \\
\hline & & & Carbon corrosion, corrosion and degradation of catalyst layers. \\
\hline Anode & More intense at the cell inlet & --- & Fuel starvation. \\
\hline \multirow{3}{*}{ Cathode } & \multirow{3}{*}{ Lower cathode over-potential } & \multirow{3}{*}{---} & Increase in mass transport losses. \\
\hline & & & Partial drop in pressure of gas. \\
\hline & & & Cathode overvoltage. \\
\hline \multirow{4}{*}{$\begin{array}{l}\text { GDL (Gas } \\
\text { Diffusion } \\
\text { Layer) }\end{array}$} & \multirow{4}{*}{---} & \multirow{4}{*}{$\begin{array}{l}\text { Oxygen gas access to cathode } \\
\text { catalyst layer and better cell } \\
\text { performance. }\end{array}$} & $\begin{array}{l}\text { Reduced pore size, poor diffusivity of gases, thus increasing the } \\
\text { concentration and surface over-potential of the fuel cell. }\end{array}$ \\
\hline & & & Blockage of pores, degradation. \\
\hline & & & Reactant starvation. \\
\hline & & & $\begin{array}{c}\text { Dissolution and diffusion of reactant gases into the liquid water } \\
\text { flood. }\end{array}$ \\
\hline \multirow{7}{*}{ MEA } & \multirow{2}{*}{$\begin{array}{l}\text { Dry cell operations over-lengthy } \\
\text { period of time can lead to irreversible } \\
\text { damage to the membrane. }\end{array}$} & \multirow{7}{*}{$\begin{array}{l}\text { Maintenance of mechanical stability } \\
\text { of the PEMFC. }\end{array}$} & Oxygen concentration decreases. \\
\hline & & & Non-uniform current density distribution. \\
\hline & Become brittle, developing cracks. & & \multirow{5}{*}{ Corrosion and degradation of electrodes. } \\
\hline & $\begin{array}{l}\text { Shrink in pores leading to low back } \\
\text { diffusion rates. Drying of the proton } \\
\text { conducting membrane. }\end{array}$ & & \\
\hline & Decrease in conductivity. & & \\
\hline & $\begin{array}{l}\text { Increased ionic resistance and ohmic } \\
\text { losses. }\end{array}$ & & \\
\hline & Increase in voltage loss. & & \\
\hline
\end{tabular}
in PEFCs [25]. Measuring the water content of a conducting PEFC is of high importance because PEFC models are designed specifically

Table 1: Effects of water on the performance of PEFCs [30-34]. 


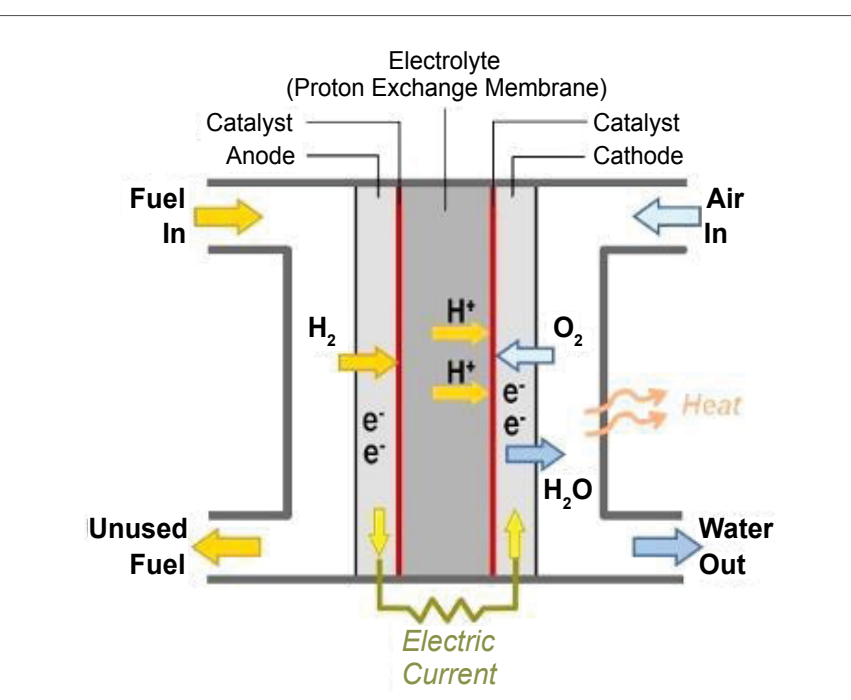

Figure 2: Schematic illustration of a proton exchange membrane fuel cell [40].

for the tests or experiments they are expected to undergo. Therefore, it is necessary to know how much water is in the fuel cell at any point during operation [38]. For the detection of water in the fuel cell, a number of detection techniques have been employed [42,43]. It is worthy to note that many of these techniques have been limited to a qualitative description of flow patterns based on certain operating conditions with respect to the resources available [44]. There are four major visualisation techniques which have been discussed as follows:-

i. Direct visualisation as a result of a transparent cell plate that makes it possible for optical devices to access the channels. These devices include digital and high-speed cameras [45]. The transparent plate also makes it possible to visualise the water directly, without requiring any external device.

ii. Gas chromatography has been used by Mench et al. [46] for the measurement of in situ distribution of water vapour, oxygen and nitrogen, with full humidification within the gas channels of the PEFC during operation. In addition to the current distribution mapping technique, the researchers were able to understand the behaviour of the cathode and anode with regards to water distribution and current density.

iii. Relative humidity (RH) has been measured using a humidity sensor by Nishikawa et al. [43] along the air flow field. Since this experiment only considered water vapour distribution, it implied that a part of the membrane in a working fuel cell was in an over-saturated condition, with the other part in an under-saturated condition which could not be achieved in a typical fuel cell.

iv. Neutron radiography, using a small-angle neutron scattering (SANS) technique [42], where the neutron radiography was used to obtain a 2D image of the liquid water in the channels. The water content of a membrane was observed with this technique, using the resulting spectra made up of the presence of intense scattering at low angles and maximum scattering (ionomer peak), which was directly related to the presence of water pools in the membrane. Neutron radiography was employed for in-situ and non-destructive imagining and also as a measurement method for detecting liquid water in a PEFC during operation [38]. This method is capable of showing the amount of water present in the gas diffusion layer (GDL), rib and flow channel $[38,47,48]$.
However, there are downsides to some of these techniques. For example, the neutron imaging and $\mathrm{x}$-rays are considerably high cost techniques. Also, there are risks associated to the use of radiation, preventing its frequent use [42]. Furthermore, as a result of the rapid weakening of the signal in the carbon layer, the nuclear magnetic resonance imaging is incapable of accessing the water content on the GDL; therefore it can only be used to detect water in the membrane. Presently, a more cost effective method has been used for the visualisation of water. This involves the use of optical devices like thermal imaging cameras or camcorders that can be obtained for prices ranging between 700 and 35,000 GBP. The cost of obtaining a thermal imaging camera is dependent on the model, pixel resolution, thermal sensitivity, field of view, infrared sensitivity, Wi-Fi connectivity and other features. A key advantage of these cameras lies in their ability to determine the presence of water within a fuel cell based on temperature gradients [49]. In addition, these are portable devices that allow fast inspection and repeated use without fear of setbacks from radiation. Finally, the time needed to set up these systems is generally shorter than the time needed to set up the gas chromatography or neutron radiography equipment.

Furthermore, the problems associated with membrane dehydration and flooding phenomena are yet to be overcome. A significant amount of research and development efforts ranging from fluid flow numerical simulations to experimental testing have been put into place in an attempt to find suitable solutions and mitigation approaches to tackle these problems [36]. Numerous studies have been done using theoretical models that help to describe the management and transportation of water in PEFCs. CFD is another tool used to study the saturation, transport and distribution of water within the PEFC [45] CFD is useful in the design process and performance analysis of fuel cells. CFD models that have been developed include zero-dimensional, one-dimensional, single-phase flow, isothermal models (involving all layers in the fuel cell stack), steady-state and single layer models. More recently, two-dimensional, two-phase flow, non-isothermal, transient, multiple layer and three-dimensional models have been proposed $[50,51]$. These will be further discussed later in section 4 .

\section{Heat and gas}

The heat losses to the environment during its operation of a PEFC are one of the main factors affecting efficiency. Hence, in order to attain high energy efficiencies, it is important that high levels of thermal integration be reached [52]. Temperature is spatially heterogeneous and under dynamic conditions and its distribution becomes irregular at different time frames. Thus, during the operation of a fuel cell, both the fluctuation on the operating parameters and the physical condition of the FC is responsible for a degree of uncertainty, leading to unstable and difficult to predict its performance. This is as a result of the level of uncertainty associated with temperature, which also is a function of ambient conditions, flow rate of reactant gases and points of operation [53].

A few papers have been published on the topic of heat losses and the effect of performance on PEFCs. Research by Schmittinger and Vahidi [22] showed that when fuel cells were operated under temperatures higher than $100^{\circ} \mathrm{C}$ there was an increase in degradation on the cell components. This brought a reduction in long-term performance and resilience. Also, the catalyst is chemically unstable at this point, leading to increased movement, sintering and accumulation of particles [54]. However, a number of advantages can be seen with the increase in temperature, such as reduced CO-poisoning, the ability to use reformed hydrogen as an alternative to pure hydrogen, increased 
catalyst tolerance for contaminants, improvement in electrochemical kinetics and efficiency, improved water management and cooling as a result of difference in temperature between fuel cell and coolant [55].

\section{Computational Fluid Dynamics in PEFC}

Computational fluid dynamics (CFD) handles the coupling of multidimensional transport phenomena in addition to electrochemical kinetics and transportation of electrons and ions that help to provide comprehensive understanding of the dynamics of fuel cells [56]. CFD is based on fluid mechanics and Navier-Stokes equations for the conversion of mass, momentum and energy equations. The CFD software carries out iterations of the Navier-Stokes and energy equations for a problem until a convergence of values is attained [57]. Laws of physics are employed in order to derive the equations for the conservation of mass, momentum and energy. These laws include: first law of thermodynamics, mass conservation and the sum of forces that equals the change of momentum.

In fuel cell modelling, CFD models can be seen as rational models that handle the important physio-chemical procedures as well as experimental observations and are a fundamental tool to ensuring that a holistic understanding of the operating of a fuel cell is achieved [16]. However, notable difficulties have been experienced in trying to carry out in-situ analysis of the fuel cell. As a result of the nature of the experimental environment, CFD methods are needed to help to simulate and determine multi-dimensional coupled fluid flow and transport of reactants, heat and charged species [14].

An operation of a PEFC involves a combination of electrochemical reactions taking place simultaneously. These include; multi-component, multi-dimensional and multi-phase fluid flow in addition to heat and mass transfer. Hence, CFD models are necessary in addition to mathematical models that would help to create a better understanding of the physical behaviour and complex phenomena taking place within the fuel cell $[58,59]$. The CFD modelling methods have been developed over the years from $2 \mathrm{D}$ models to the improved computational models that account for fluid flow, thermal and electrochemical transport, 3D geometries and 2-phase transportations [14]. However, the challenges yet to be won to ensure proper functional and predictive capabilities of the CFD models include:

i. Inadequate general models for ionic transportation of water in polymer membranes.

ii. The majority of CFD models for PEFCs consider analytical, semi-empirical $1 \mathrm{D}$ and $2 \mathrm{D}$ PEFC models, without considering the effects of flooding by liquid-water on performance of the stack [60].

iii. Inadequate macroscopic exhibiting and determination of catalyst layers.

iv. Inadequate information in in-situ data validation for transport and material factors.

v. Wide range of time scales.

Djilali [16] further mentioned that to bring about notable improvements and developments in cost, innovative designs and lead operation times, coupling of computational fluid dynamics (CFD) models with multi-disciplinary optimisation procedures has to take place, in order to provide an opportunity for the development of computational fuel cell engineering (CFCE) tools. In addition, the cost of CFD modelling of a 3D PEFC model is large and can be seen as not practical in certain computing environments because it can be time consuming and requires powerful computational resources. Modelling can be computationally demanding due to the differences on the geometric dimensions of the various parts and regions of the fuel cell [61]. For example, in a typical fuel cell the thickness of a stack is in the range of $1-2 \mathrm{~mm}$ and thickness of the anode and cathode catalyst layers is in the range of 10 to $20 \mu \mathrm{m}$ and the overall height and width dimensions are in the range of 10 to $20 \mathrm{~cm}$.

According to Gurau et al. [62], the governing differential equations for the gas flow channels and gas diffusion electrodes can be joined for both regions because they are similar, thus leading to a computational effect of one domain without any internal boundary conditions. The material properties and source terms acknowledge the two regions and take different values of interest to form one domain; leading to the single-domain approach $[63,64]$. Computational fluid dynamics (CFD) has come to play an important part of the design and fabrication of products and systems in recent times. CFD is often said to be a fluid version of finite element analysis, as will be further discussed. This is because it is possible to run simulation tests on a number of design iterations and compare results to see the best course of action. This step greatly reduces the need to build prototypes that can be both costly and time consuming. CFD methodologies are being used in different fields, from the propulsion industry to car, ship and turbo-machinery designs $[65,66]$. The evolution from the use of $2 \mathrm{D}$ flow models, as mentioned earlier, to Euler equations and 3D Navier- Stokes applications can be attributed to the rapid computer power increase and improvements in CFD methodologies and algorithms [57].

Also, CFD models are useful for an analysis of phenomena such as heat and mass transfer, fluid and two-phase flows through a particular cell, based on a finite-element framework [67]. Sivertsen and Djilali [14] suggested that simulations under realistic conditions were important for the continuous development and optimization, commercialisation and the use of cheaper materials for improved design and fabrication of fuel cells in the coming years. This is evident in comparisons between model test experiments and computer-based simulations. CFD software packages can be applied in many other areas, for example, in the flow analysis of wind in a turbine. These software packages are designed in such a way that it is possible to enter parameters such as velocity, pressure and direction of the wind into the program. Hence it is possible to predict the behaviour and performance of the model being studied, and also helps to identify areas of increased temperature to optimise cooling, overall temperature and other required parameters [57].

CFD for the Fuller and Newman [68] modelling of fuel cells was first introduced by Gurau et al. [62] with a 2D calculation of coupling the fluid flow, mass transfer and electro-kinetics, while eliminating the need for artificial boundary conditions at internal interfaces. The revolutionary modelling work was initially done by Bernardi and Verbrugge [69,70] and Springer et al. [71,72], assuming a 1D flow through the layers of the PEFC. Nguyen and White [73] later created a pseudo-2D heat and mass transfer model that also showed the effect of reactant consumption along the flow channels. While Fuller and Newman [68] used a similar 2D model method to understand the relationship between water and thermal management.

Since the beginning of the century, the behaviour of water/vapour in fuel cells has become a central topic in many literature works [74]. Baschuk and Li [75] developed a model showing the effect of water in both the GDL and catalyst layer of the cathode, on overall fuel cell performance. Over the years, it was noted that a number of fuel cell models had been developed, like the single and two-phase models, 
that considered the effect of the liquid water supplied to the anode and that formed in the cathode. However, as a result of the slow kinetics of oxygen reduction as mentioned earlier, some models were focused on the fuel cell cathode. Jiao and Zhou [76] and others focused on the fuel cell as a whole [77]. One of the most comprehensive 3D multiphase works was done by Berning and Djilali [15]. Their research covered an analysis of the role of the gas diffusion layer (GDL) as the main component of the multiphase treatment and the introduction of the multiphase approach for the cathode and anode in 3D plots, showing cell length and width of the GDL. However, shortcomings of this research lay in the absence of a comparison of simulation results with experimental data on a fuel cell [2].

It is worthy to note that the innovative approach of Bernardi and Verbrugge $[69,70]$ served as a framework that brought about the multidimensional and multi-physics models in existence today. However, that research work only involved one-dimensional models, with the assumption that the water in the electrodes was only in vapour form thus providing very narrow applicability to actual PEFCs performance where flooding is concerned [56, 78]. This is also the case for the twodimensional models developed afterwards by Fuller and Newman [68] and Nguyen and White [73]. Although their pseudo-two-dimensional models revealed the effect of heat and water management on the performance of PEFCs, which led to the concept of modelling proposed by Gurau et al. [62]. There are still limitations with regards to high fuel utilisation and low humidity circumstances in commercial-scale fuel cells.

In addition, CFD simulations are directed at gaining a better understanding of a model PEFC, helping in the prediction of fluid behaviour within the PEFC by carrying out a simulation of its performance [61] to describe in the fluid flow within the PEFC, simulation programs are used more conveniently to develop models, set suitable work conditions, generate mesh and run the calculations. The use of the CFD framework for modelling the PEFC has been developed further from $2 \mathrm{D}$ and $3 \mathrm{D}$ simulations of coupled electrochemical and transport processes with the aid of CFD codes. Later on, Dutta et al. [79], went on to present a $3 \mathrm{D}$ simulation using a commercial CFD package, FLUENT. The subsequent simulations by Nguyen and White [73], represented the MEA (membrane electrode assembly) as an interface without thickness in the computational domain, causing a drop in water transport and Ohmic potential across the membrane [56].

Over recent years, further CFD simulations are being carried out with improved commercial packages, such as FLUENT, FEMLAB, CFX-5, STAR-CD and STAR-CCM+, just to name a few from the various suppliers that give room for users to make use of their own models [51,61]. For example, FLUENT is a finite volume code that can be used to solve the coupled equation of mass conservation, mass diffusion and momentum conservation [80]. These commercial CFD packages are capable of balancing and solving uncommon water equations, as is the nature of PEM fuel cells when modelling. Although STAR-CD is no longer in use and has now been replaced with STAR $\mathrm{CCM}+$ by CD ADAPCO. These software packages need to be selected depending on the specific requirements of a task ranging from heat and mass transfer to electrical power generation and so on.

Complete CFD modelling of PEMFCs is made up of the creation of a 3D model and introducing meshing, mathematical and numerical solving techniques. With the aid of commercial CFD packages, some aspects of the modelling process is simplified, but with the challenge of producing reliable results. Shan and Choe [81] mentioned in their review that models of PEFCs available now are based on either empirical or 3D CFD, which do not meet the needs that require physical representation of the behaviour of a stack as a result of complexity or even simplicity. The processes that take place within the fuel cell during its operation comprise of many small complex operations that make these models incapable of fully simulating the actual working of the fuel cell at all times.

\section{Validation of CFD Simulations}

Validation involves the assessment of simulation results using experimental data as a benchmark for the estimation of errors [82]. In order to confirm accuracy and reliability of CFD results, careful validation is required, where validation serves as a means of ensuring that the correct mathematical model is used as an accurate representation because it meets specific performance criteria [83]. There are many techniques that can be used for the validation of CFD with respect to the needs of the project. The most common type of validation involves a comparison of simulation results with experimental data. A general sense of agreement between the experiment and computation results can provide validation. This method of validation is also useful for creating assurance in the model. Another method involves the use of test rigs that help with the maintenance of control over fuel cells, while ensuring safe and reliable operations. With the aid of a test rig, the conditions such as load, gas flow, gas flow conditioning, humidification of the gases, operating temperature, pressure, gas stoichiometry and utilisation, differential pressure, single cell voltages, gas leakage, overheating and cell reversal can be monitored.

During an operation of a PEFC, a sufficient supply of pure hydrogen is required, as well as oxygen/ air. Contamination by $\mathrm{CO}_{2}$ in large quantities up to $500 \mathrm{ppm}$ can have a negative impact on the performance of the PEFC. However, trace quantities of $\mathrm{CO}_{2}$, around $100 \mathrm{ppm}$ can be managed when monitored closely and conditioned by adding a small quantity of oxygen/air. When the fuel cell is operated under increased pressures, the power density also increases, thus elevating problems that may arise from water loss in the membrane. In order to maintain the high conductivity state of the membrane electrolytes, a certain level of humidification of the gases is required. Also, the production of heat as a result of the electrochemical electricity generation from hydrogen needs to be monitored in order to prevent the fuel cell from overheating. Besides comparing simulation results with experimental data, the other methods that can be used to validate CFD simulations include:

\section{i. Comparing simulation results with analytical equations.}

ii. Checking mesh convergence. This method allows for assessing the robustness of the model.

iii. Comparing results from two different packages.

iv. Comparing simulation results from existing literature.

The methods for validation listed above (including validation from experimental data) can be performed either independently or concurrently, depending on the resources available and complexity of the problem. For example, a test rig might not be readily available, in another case, there might not be access to another package or data from literature for a specific simulation is non-existent.

\section{Concluding Remarks}

One of the major factors that influenced the development of fuel cells is the worldwide concern about the environmental 
Citation: Chen Y, Enearu OL, Montalvao D, Sutharssan T (2016) A Review of Computational Fluid Dynamics Simulations on PEFC Performance. J Appl Mech Eng 5: 241. doi: 10.4172/2168-9873.1000241

Page 7 of 9

consequences of fossil fuels. These fuels are massively used in the dayto-day production of electricity and propulsion of vehicles for example. Careful consideration needs to be taken for all components and their interactions, from the appropriate cell type to the right fuel and system requirements. Hydrogen and fuel cell systems may be a solution for the sustainable power generation that the world needs today. Benefits can be seen when public incentives and private contributions are put in place to motivate the development of the power generation market in general. However, challenges need to be won before fossil fuels can take a back seat in energy provision.

In addition, CFD serves as an alternative to the modelling of the complex governing equations used to calculate and solve fluid flow problems within PEFCs and other applications spanning across various fields of study, from automotive engineering to aerospace and even medicine. However, there are a number of limitations that can be associated with the use of CFD, for example human, truncation or numerical errors. Inaccuracies can result from the inability of untrained users to spot errors and provide adequate input for the required simulation. CFD contributes to the understanding of underlying physics within fuel cells, involving electrochemical and kinetic variables like current density and water transport in individual cells. CFD models are therefore able to predict failures that may arise from flooding or dehydration of the membrane or other operating conditions that can bring about failure of fuel cells. Also, the ease and speed of running simulations contribute to the positive prospects and advantages of CFD. With the aid of commercial packages the need to constantly make improvements in user interfaces as more complicated designs are made, CFD will continue to undergo advances with benefits for the industries developing fuel cell systems.

In conclusion, the interest in CFD is expanding, as computational modelling makes it possible to evaluate innovative designs and assess the performance of fuel cells. In the long run, with regards to the ability of CFD to predict performance of fuel cells, it will help to improve their marketability, reliability and confidence in designs. However, most of the theoretical models concentrate on steady-state condition analysis, while transient transport behaviours still need to be considered. Also, due to the numerical computation workload required for PEFCs with complex flow fields, more focus has been put into simple flow fields and channels, leaving the problems associated with complex flow fields a challenge to be solved. Proper water management of the PEFC involves maintaining hydration of the membrane without flooding the electrode, while keeping a dynamic balance of water in the membrane during operation. Hence, proper water management and overall performance and marketability can be achieved in the future if and only if these challenges are overcome in order to speed up commercialisation efforts.

\section{References}

1. Carrette L, Friedrich AA, Stimming U (2000) Fuel cells: Principles, types, fuels, and applications. Chem Phys Chem 1: 162-193.

2. Cordiner S, Lanzani SP, Mulone V (2011) 3D effects of water-saturation distribution on polymeric electrolyte fuel cell (PEFC) performance. Int J Hydrogen Energy 36: 10366-10375.

3. Dincer I, Rosen MA (2011) Sustainability aspects of hydrogen and fuel cell systems. Energy for Sustainable Development 15: 137-146.

4. Frey HC, Rouphail NM, Zhai H, Farias TL, Gonçalves GA (2007) Comparing real-world fuel consumption for diesel-and hydrogen-fuelled transit buses and implication for emissions. Transportation Research Part D: Transport and Environment 12: 281-291.

5. Yuan W, Tang Y, Pan M, Li Z, Tang B (2010) Model prediction of effects of operating parameters on proton exchange membrane fuel cell performance. Renewable Energy 35: 656-666.

6. Barbir F (2013) PEM fuel cells: Theory and practice. (2ndedn) London: Elsevier Inc. Academic Press.

7. Çelik M, Özışık G, Genç G, Yapıcı H (2014) The effect of microporous layer in phosphoric acid doped polybenzimidazole polymer electrolyte membrane fuel cell. J Appl Mech Eng 3: 2.

8. Gasteiger H, Panels J, Yan S (2004) Dependence of PEM fuel cell performance on catalyst loading. J Power Sources 127: 162-171.

9. Srinivasulu GN, Subrahmanyam T, Rao VD (2011) Parametric sensitivity analysis of PEM fuel cell electrochemical Model. Int j hydrogen energy 36 14838-14844. PEMFC 2014, Fuel cell today, Technologies.

10. Wang Y, Chen KS, Mishler J, Cho SC, Adroher XC (2011) A review of polymer electrolyte membrane fuel cells: Technology, applications, and needs on fundamental research. Applied Energy 88: 981-1007.

11. Williams RH, Larson ED, Katofsky RE, Chen J (1995) Methanol and hydrogen from biomass for transportation. Energy for Sustainable Development 1: 18-34

12. Yang WJ, Wang HY, Lee DH, Kim YB (2015) Channel geometry optimization of a polymer electrolyte membrane fuel cell using genetic algorithm. Applied Energy 146: 1-10.

13. Sivertsen B, Djilali N (2005) CFD-based modelling of proton exchange membrane fuel cells. J Power Sources 141: 65-78.

14. Berning T, Djilali N (2003) Three-dimensional computational analysis of transport phenomena in a PEM fuel cell- a parametric study. J Power Sources 124: $440-452$.

15. Djilali N (2007) Computational modelling of polymer electrolyte membrane (PEM) fuel cells: challenges and opportunities. Energy 32: 269-280.

16. Song C (2002) Fuel processing for low-temperature and high-temperature fuel cells: Challenges, and opportunities for sustainable development in the 21st century. Catalysis today $77: 17-49$.

17. Lepiller C (2013) Fuel cell basics, Pragma Industries

18. Das PK, Li X, Liu ZS (2010) Analysis of liquid water transport in cathode catalyst layer of PEM fuel cells. Int j hydrogen energy 35: 2403-2416.

19. Kanani H, Shams M, Hasheminasab M, Bozorgnezhad A (2015) Model development and optimization of operating conditions to maximize PEMFC performance by response surface methodology. Energy Conversion and Management 93: 9-22.

20. Santarelli M, Torchio M (2007) Experimental analysis of the effects of the operating variables on the performance of a single PEMFC. Energy Conversion and Management 48: 40-51.

21. Schmittinger W, Vahidi A (2008) A review of the main parameters influencing long-term performance and durability of PEM fuel cells. Journal of Power Sources 180: 1-14.

22. Amirinejad M, Rowshanzamir S, Eikani MH (2006) Effects of operating parameters on performance of a proton exchange membrane fuel cell. J Power Sources 161: 872-875

23. Liu X, Guo H, Ye F, Ma CF (2007) Water flooding and pressure drop characteristics in flow channels of proton exchange membrane fuel cells. Electrochimica Acta 52: 3607-3614.

24. Anderson R, Zhang L, Ding Y, Blanco M, Bi X, et al. (2010) A critical review of two-phase flow in gas flow channels of proton exchange membrane fuel cells. J Power Sources 195: 4531-4553.

25. Kraytsberg A, Ein-Eli Y (2006) PEM FC with improved water management. J Power Sources 160: 194-201.

26. Houreh NB, Afshari E (2014) Three-dimensional CFD modeling of a planar membrane humidifier for PEM fuel cell systems. Int J Hydrogen Energy 39: 14969-14979.

27. Jiao K, Li X (2011) Water transport in polymer electrolyte membrane fuel cells Progress in Energy and Combustion Science 37: 221-291.

28. Koulouris K, Konstantopoulos G, Apostolopoulos A, Matikas T, Apostolopoulos C (2016) The Influence of Corrosion Damage on Low Cycle Fatigue Life of Reinforcing Steel Bars S400. J Applied Mechanical Engineering. 
Citation: Chen Y, Enearu OL, Montalvao D, Sutharssan T (2016) A Review of Computational Fluid Dynamics Simulations on PEFC Performance. J Appl Mech Eng 5: 241. doi: 10.4172/2168-9873.1000241

Page 8 of 9

29. Deevanhxay P, Sasabe T, Tsushima S, Hirai S (2013) Effect of liquid water distribution in gas diffusion media with and without microporous layer on PEM fuel cell performance. Electrochemistry Communications 34: 239-241.

30. Natarajan D, Van Nguyen T (2003) Three-dimensional effects of liquid water flooding in the cathode of a PEM fuel cell. J Power Sources 115: 66-80.

31. Park S, Lee JW, Popov BN (2012) A review of gas diffusion layer in PEM fuel cells: materials and designs. Int $\mathrm{J}$ of hydrogen energy $37: 5850-5865$.

32. Wang X, Van Nguyen T (2012) An experimental study of the liquid water saturation level in the cathode gas diffusion layer of a PEM fuel cell. J Power Sources 197: 50-56.

33. Wood DL, Jung SY, Nguyen TV (1998) Effect of direct liquid water injection and interdigitated flow field on the performance of proton exchange membrane fuel cells. Electrochimica Acta 43: 3795-3809.

34. Litster S, Sinton D, Djilali N (2006) Ex situ visualization of liquid water transport in PEM fuel cell gas diffusion layers. J Power Sources 154: 95-105.

35. Li H, Tang Y, Wang Z, Shi Z, Wu S, et al. (2008) A review of water flooding issues in the proton exchange membrane fuel cell. J Power Sources 178: 103117.

36. Bazylak A (2009) Liquid water visualization in PEM fuel cells: A review. Int J Hydrogen Energy 34: 3845-3857.

37. Chen YS, Peng H, Hussey DS, Jacobson DL, Tran DT, et al. (2007) Water distribution measurement for a PEMFC through neutron radiography. J Power Sources 170: 376-386.

38. Satija R, Jacobson DL, Arif M, Werner S (2004) In situ neutron imaging technique for evaluation of water management systems in operating PEM fuel cells. J Power Sources 129: 238-245.

39. (2015) Fuel Cell Technology: How it works. Catalysis today: Clean power solutions.

40. Zhang X, Gao Y, Ostadi H, Jiang K, Chen R (2014) A proposed agglomerate model for oxygen reduction in the catalyst layer of proton exchange membrane fuel cells. Electrochimica Acta 150: 320-328.

41. Mosdale R, Gebel G, Pineri M (1996) Water profile determination in a running proton exchange membrane fuel cell using small-angle neutron scattering. $J$ Membrane Science 118: 269-277.

42. Nishikawa H, Kurihara R, Sukemori S, Sugawara T, Kobayasi H, et al. (2006) Measurements of humidity and current distribution in a PEFC. J Power Sources 155: 213-218.

43. Hussaini IS, Wang CY (2009) Visualization and qualification of cathode channe flooding in PEM fuel cells. J Power Sources 187: 444-451.

44. Ji M, Wei Z (2009) A review of water management in polymer electrolyte membrane fuel cells. Energies 2: 1057-1106.

45. Mench M, Dong Q, Wang C (2003) In situ water distribution measurements in a polymer electrolyte fuel cell. J Power Sources 124: 90-98.

46. Turhan A, Heller K, Brenizer J, Mench M (2006) Quantification of liquid water accumulation and distribution in a polymer electrolyte fuel cell using neutron imaging. J Power Sources 160: 1195-1203.

47. Zhang J, Kramer D, Shimoi R, Ono Y, Lehmann E, et al. (2006) In situ diagnostic of two-phase flow phenomena in polymer electrolyte fuel cells by neutron imaging: Part B. Material variations. Electrochimica Acta 51: 2715-2727.

48. Scott P (2012) Experimental investigation of a novel design concept of a modular PEMFC stack. UK University of Hertfordshire.

49. Carton J, Lawlor V, Olabi A, Hochenauer C, Zauner G (2012) Water drople accumulation and motion in PEM (Proton Exchange Membrane) fuel cell minichannels. Energy 39: 63-73.

50. Young JB (2007) Thermofluid modeling of fuel cells. Annu Rev Fluid Mech 39: 193-215.

51. Uriz I, Arzamendi G, Diéguez P, Echave F, Sanz O, et al. (2014) CFD analysis of the effects of the flow distribution and heat losses on the steam reforming of methanol in catalytic $(\mathrm{Pd} / \mathrm{ZnO})$ microreactors. Chemical Engineering Journal 238: 37-44.

52. Noorkami M, Robinson JB, Meyer Q, Obeisun OA, Fraga ES, et al. (2014) Effect of temperature uncertainty on polymer electrolyte fuel cell performance. Int j hydrogen energy 39: 1439-1448.
53. Song Y, Xu H, Wei Y, Kunz HR, Bonville LJ, et al. (2006) Dependence of hightemperature PEM fuel cell performance on Nafion $囚$ content. J power sources 154: $138-144$.

54. Zhang J, Xie Z, Zhang J, Tang Y, Song C, et al. (2006) High temperature PEM fuel cells. J power Sources 160: 872-891.

55. Wang CY (2004) Fundamental models for fuel cell engineering. Chemical reviews 104: 4727-4766.

56. Hirsch C (2007) Numerical computation of internal and external flows: The fundamentals of computational fluid dynamics: The fundamentals of computational fluid dynamics: butterworth-heinemann 680 .

57. Le AD, Zhou $B$ (2008) A general model of proton exchange membrane fuel cell. J power sources 182: 197-222.

58. Ferreira RB, Falcão D, Oliveira V, Pinto A (2015) Numerical simulations of twophase flow in an anode gas channel of a proton exchange membrane fuel cell. Energy 82: 619-628.

59. Dawes J, Hanspal N, Family O, Turan A (2009) Three-dimensional CFD modelling of PEM fuel cells: an investigation into the effects of water flooding. Chemical Engineering Science 64: 2781-2794.

60. Guvelioglu GH, Stenger HG (2005) Computational fluid dynamics modeling of polymer electrolyte membrane fuel cells. J Power Sources 147: 95-106.

61. Gurau V, Liu H, Kakac S (1998) Two-dimensional model for proton exchange membrane fuel cells. AIChE Journal 44: 2410-2422.

62. Cheddie D, Munroe N (2005) Review and comparison of approaches to proton exchange membrane fuel cell modeling. J Power Sources 147: 72-84.

63. Patankar S (1980) Numerical heat transfer and fluid flow: CRC Press.

64. Blazek J (2001) Computational fluid dynamics: principles and applications. The Netherlands: Elsevier Ltd.

65. Arvay A, Ahmed A, Peng XH, Kannan A (2012) Convergence criteria establishment for 3D simulation of proton exchange membrane fuel cell. Int J hydrogen energy $37: 2482-2489$.

66. Weber AZ, Newman J (2004) Modeling transport in polymer-electrolyte fue cells. Chemical reviews 104: 4679-4726.

67. Fuller TE, Newman J (1993) Water and thermal management model for protonexchange membrane fuel cells. J Electrochemical Society 140: 1218-1225.

68. Bernardi DM, Verbrugge MW (1991) Mathematical model of a gas diffusion electrode bonded to a polymer electrolyte. AIChE Journal 37: 1151-1163.

69. Bernardi DM, Verbrugge MW (1992) A mathematical model of the solidpolymer-electrolyte fuel cell.

70. J Electrochemical Society 139: 2477-2791.

71. Springer T, Wilson M, Gottesfeld S (1993) Modeling and experimental diagnostics in polymer electrolyte fuel cells. Journal of the Electrochemical Society 140: 3513-3526

72. Springer TE, Zawodzinski T, Gottesfeld S (1991) Polymer electrolyte fuel cell model. J Electrochemical Society 138: 2334-2342.

73. Nguyen TV, White RE (1993) A water and heat management model for protonexchange-membrane fuel cells. J Electrochemical Society 140: 2178-2786.

74. Chen YS, Peng $H$ (2008) A segmented model for studying water transport in a PEMFC. J Power Sources 185: 1179-1192.

75. Baschuk J, Li X (2000) Modelling of polymer electrolyte membrane fuel cells with variable degrees of water flooding. J power sources 86: 181-196.

76. Jiao K, Zhou B (2008) Effects of electrode wettabilities on liquid water behaviours in PEM fuel cell cathode. J Power Sources 175: 106-119.

77. Grujicic M, Chittajallu K (2004) Optimization of the cathode geometry in polymer electrolyte membrane (PEM) fuel cells. Chemical Engineering Science 59: 5883-5895.

78. He W, Yi JS, Van Nguyen T (2000) Two-phase flow model of the cathode of PEM fuel cells using interdigitated flow fields. AIChE Journal 46: 2053-2064.

79. Dutta S, Shimpalee S, Van Zee J (2001) Numerical prediction of massexchange between cathode and anode channels in a PEM fuel cell. Int J Heat and Mass Transfer 44: 2029-2042. 
Citation: Chen Y, Enearu OL, Montalvao D, Sutharssan T (2016) A Review of Computational Fluid Dynamics Simulations on PEFC Performance. J Appl Mech Eng 5: 241. doi: 10.4172/2168-9873.1000241

Page 9 of 9

80. Ramos-Alvarado B, Hernandez-Guerrero A, Juarez-Robles D, Li P (2012) Numerical investigation of the performance of symmetric flow distributors as flow channels for PEM fuel cells. Int J hydrogen energy 37: 436-448.

81. Shan Y, Choe SY (2006) Modeling and simulation of a PEM fuel cell stack considering temperature effects. J Power Sources 158: 274-286.
82. Stern F, Wilson RV, Coleman HW, Paterson EG (1999) Verification and validation of CFD simulations: Iowa Institute of Hydraulic Research, University of lowa.

83. Oberkampf WL, Trucano TG (2000) Validation methodology in computational fluid dynamics. AIAA paper 2549: 19-22. 